Rozprawy Komisji Językowej ŁTN, t. LXVII, 2019

ISSN 0076-0390; e-ISSN 2450-9310

https://doi.org/10.26485/RKJ/2019/67/20

Maciej Rak*

(D) https://orcid.org/0000-0003-0042-1406

\title{
WIELOJEZYCZNOŚĆ I WIELOKULTUROWOŚĆ PRZEDWOJENNEGO LWOWA I CZERNIOWIEC W ŚWIETLE FRAZEMATYKI
}

\author{
MULTILINGUALISM AND MULTICULTURALISM IN PRE-WAR LVIV \\ AND CHERNIVTSI IN THE CONTEXT OF PHRASEMATICS
}

The article concerns the phrasematics of the Polish language of pre-war Lviv and Chernivtsi. These cities were multilingual and multicultural, and the Polish language was represented there by the South-Eastern dialect. Foreign influences in the Lviv and Chernivtsi phrasematics can be summarized as: citation, calque, half-calqua, as well as lexical borrowings, on the basis of which phrasemes were created.

Keywords: phrasematics, Polish language of pre-war Lviv, Polish language of pre-war Chernivtsi Słowa kluczowe: frazematyka, polszczyzna przedwojennego Lwowa, polszczyzna przedwojennych Czerniowiec

\section{UWAGI WSTEPNE}

Podstawę materiałową tego artykułu stanowią frazemy (czyli ,trwałe formy językowe, które w danej sytuacji stały się - niezależnie od swych cech strukturalnych i semantycznych - przyjętym sposobem wyrażania danego potencjału treściowego" [Chlebda, 2010, s. 336], poza frazeologizmami w tradycyjnym ujęciu są w tej grupie także przysłowia i porównania) wynotowane z Polszczyzny Lwowa i kresów potudniowo-wschodnich do 1939 roku Zofii Kurzowej (dalej PLK) oraz z Bukowiny mojej miłości. Stownika Kazimierza Feleszki (dalej BMM). Część tego materiału omówiłem w dwóch artykułach, które ukazały się drukiem

* Uniwersytet Jagielloński, Wydział Polonistyki, Katedra Historii Języka i Dialektologii, ul. Gołębia 18, 31-007 Kraków; e-mail: maciej.rak@uj.edu.pl. 
w Rumunii [Rak, 2009] i na Ukrainie [Rak, 2010]. Po dziesięciu latach wracam jednak do zasygnalizowanej wówczas problematyki obcych wpływów we frazematyce polszczyzny południowokresowej, aby jeszcze dokładniej uchwycić zależności międzyjęzykowe i międzykulturowe.

Zasób frazematyczny PLK i BMM jest różny. Łącznie (wliczając jednostki zapożyczone, charakterystyczne dla dialektu południowokresowego i wspólne z polszczyzną ogólną oraz potoczną) pierwszy zbiór zawiera około 130 frazemów, a drugi około 200. Nie ma całkowitej pewności co do liczby jednostek i nie jest to spowodowane tylko względami terminologicznymi, czyli rozgraniczaniem tego, co jest frazemem, a co nim nie jest. Jak się bowiem okazuje, niektóre frazemy nie zostały wyodrębnione jako oddzielne hasła, lecz znajdują się w cytatach użycia. Dotarcie do tych jednostek jest więc w pewnym stopniu utrudnione.

Międzywojenna (z tego okresu pochodzi omawiany materiał) sytuacja Lwowa i Czerniowiec była pod względem wymienionych czynników odmienna. Lwów była jednym z najważniejszych polskich miast, z kolei Czerniowce znajdowały się w graniach Rumunii. Jak podaje Drugi powszechny spis ludności z dnia 9 XII 1931 r. Ludność obecna wedlug języka ojczystego na podstawie spisu z dnia 9 XII 1931 r. [Szturm de Sztrem, 1932], populacja Lwowa liczyła 316177 osób, spośród których 201 481, czyli 63,7\% posługiwało się polszczyzna. Inaczej było w Czerniowcach - tu w 1930 roku na 112427 osób tylko 8986 (czyli około 8\%) deklarowało język polski [https://uk.wikipedia.org/wiki/Haceлення_Чернівців]. W obydwu miastach był to dialekt południowokresowy, choć nieco się różniący [Feleszko, 2002, s. 174]. We Lwowie językiem urzędowym była polszczyzna, w Czerniowcach rumuński, we Lwowie działało wiele polskich instytucji kulturalno-oświatowych, w Czerniowcach nieporównywalnie mniej.

Podane w poprzednim akapicie czynniki wpłynęły też na odmienną sytuację językową w obydwu miastach. W odniesieniu do Czerniowiec i ogólnie Bukowiny Karpackiej omówili ją Kazimierz Feleszko (por. artykuły zebrane w pierwszym tomie Bukowiny mojej miłości [Feleszko, 2002]) i Helena Krasowska [np. 2000; 2004; 2005; 2006; 2010a; 2010b; Greń, Krasowska, 2008, s. 8-13], z kolei sytuację we Lwowie dokładnie scharakteryzowały Zofia Kurzowa [PLK] i Irena Seiffert-Nauka [1992]. Nie wchodząc zbytnio w szczegóły, można stwierdzić, że we Lwowie polszczyzna stykała się z językami: niemieckim (język administracji galicyjskiej i pewnej grupy mieszkańców, którzy osiedlili się w okresie austro-węgierskim), ukraińskim (język części mieszkańców miasta i większości okolicznych wsi), a także jidysz i hebrajskim (języki społeczności żydowskiej, pierwszy używany w kontaktach codziennych, drugi w liturgii). W Czerniowcach do tego zestawu doszedł język rumuński (urzędowy i większości mieszkańców). 
Co zrozumiałe, lwowianie i czerniowiczanie byli albo wielojęzyczni, albo stykali się z wielojęzycznością.

Ślady skomplikowanych relacji językowych widać we frazematyce na kilka sposobów. Są to cytaty (jednostki przejęte z innego języka do polszczyzny w znaczeniu i postaci fonetycznej identycznej lub niemal identycznej), kalki frazematyczne (frazemy utworzone z rodzimych elementów według obcych wzorów), półkalki (frazemy utworzone według obcych wzorów z rodzimych elementów i zapożyczeń) i zapożyczenia poszczególnych wyrazów, które już na gruncie polskim stały się podstawą frazemów. Zjawisko kalkowania dokładnie opisał Jerzy Obara [1986; 1989a; 1989b]. W odniesieniu do frazeologii uwagi teoretyczne na temat kalk, półkalk i hybryd znajdziemy w artykule Stanisława Staszewskiego [1985], za którym tak właśnie pojmuję te terminy. Warto nadmienić, że zapożyczenia frazematyczne (głównie kalki) były tematem konferencji Славянская фразеология. Заимствования и кальки в славянской фразеологии, która odbyła się w Petersburgu w dniach 20-21 marca 2019 roku.

\section{WIELOJĘZYCZNOŚĆ FRAZEMATYKI LWOWA I CZERNIOWIEC}

$\mathrm{W}$ analizie pomijam te przykłady, w których mamy do czynienia $\mathrm{z}$ dawnymi zapożyczeniami (np.: dać szluga [BMM, s. 209] - niem. Schluck; frajer pompka [PKL, s. 267]-niem. Freier), rozpowszechnionymi w polszczyźnie ogólnej i/lub potocznej, gdyż tego typu jednostki nie oddają specyfiki sytuacji językowej Lwowa i Czerniowiec.

\subsection{Cytaty}

Cytaty z języka ukraińskiego i gwar ukraińskich w podobnej liczbie zostały zanotowane w PLK i BMM, por.:

1) Ahi na usi! 'do diabła ze wszystkim' [BMM, s. 46], ukr. buk. Azi на yсi;

2) Ahi pakaty! 'do licha' [BMM, s. 46], ukr. buk. Агi пакати z rum. păcat 'grzech, też diabel';

3) Bih me 'używane jako zapewnienie' [PLK, s. 389], ukr. Бiz мe;

4) Chytro mudro 'przebiegle' [PLK, s. 270], ukr. Xитро мудро;

5) Cur tobi, pek tobi, ot se na! 'wykrzyknienie dla odparcia przeciwnika' [PLK, s. 425], ukr. Цур тобі, пек тобі, от се на;

6) Duch toj pitiuch 'człowiek mizernej postury, chuchro, chucherko' [BMM, s. 78], ukr. Дух той nimyx;

7) Durnyj pip tebe (joho) chrestyw 'o kimś, kto jest głupi' [BMM, s. 166], ukr. Дурний піп тебе хрестив; 
8) Git'ku róhatyj 'diabeł rogaty, tylko w wyzwiskach lub przekleństwach' [BMM, s. 88], ukr. buk. Гітько рогатий;

9) Git'ku surukaty 'diabeł wcielony, tylko w wyzwiskach i przekleństwach' [BMM, s. 88], ukr. buk. Гітько сурукатий;

10) Hojda Maryna 'wielka, rosła kobieta (też zamaszysta)' [PLK, s. 267; BMM, s. 101], ukr. Гойда Марина;

11) Hoła sraka pusipaka 'biedak, obdartus, włóczęga, człowiek z marginesu' [BMM, s. 173], ukr. Гола срака посіпака;

12) Koty tam 'kiedy' [PLK, s. 270], ukr. Коли то;

13) Mensze bilsze 'mniej więcej' [PLK, s. 270], ukr. Біли менш;

14) Na selo ludy duryty! 'używane jako zaprzeczenie' [PLK, s. 389], ukr. На село людей дурити;

15) Na strym hołowu 'na złamanie karku, bardzo szybko' [BMM, s. 205], ukr. На струм голову;

16) Pad'ku moj! 'wykrzyknik używany przy odebraniu nieszczęśliwej wiadomości' [PLK, s. 425], ukr. Падку мій;

17) Sczeznij w tristia! 'odczep się' [PLK, s. 425], ukr. Щезни в крістя;

18) Tuda siuda 'tędy owędy, tu i tam' [PLK, s. 270], ukr. Туди сюди.

Cytaty z języka rumuńskiego były używane tylko w polszczyźnie czerniowieckiej, por:

1) Bilet de identitate 'dowód osobisty' [BMM, s. 54], rum. Bilet de identitate;

2) Czerku de kontrare 'okregowa komisja poborowa' [BMM, s. 69], rum. Cercul de recrucare;

3) Czertifikat dy nasztery 'metryka urodzenia' [BMM, s. 70], rum. Certificat de naștere;

4) Fudulija boului 'zarozumialstwo' [BMM, s. 85], rum. Fudulia boului;

5) Hopa mitika 'zabawka samowstająca, „Wańka-wstańka”' [BMM, s. 102], rum. Hopa Mitică - od pierwszych słów rymowanki Hopă Mitica, cînd cade nu se strică [BMM, s. 102];

6) Impjegat de gare 'dyżurny ruchu' [BMM, s. 103], rum. Impiegat de gară;

7) Kum se cade 'wybornie, jak należy' [BMM, s. 123], rum. Cum se cade;

8) Szef de gare 'zawiadowca stacji' [BMM, s. 208], rum. Şef de gară;

9) Tadż dyn gura (tadżdyngura) 'zamknij się' [BMM, s. 219], rum. Tace din gură;

10) Waj dé miné 'okrzyk zgrozy, przestrachu, rozpaczy' [BMM, s. 231], rum. Vai de mine!;

11) Wajdykapul meu! 'okrzyk rozpaczy' [BMM, s. 231], rum. Vai de capul meu!. 
Mniej liczną grupę stanowią cytaty z jidysz, por.:

1) A lecter sof! 'sytuacja bez wyjścia' [BMM, s. 45], jid. A lecter sof!;

2) Cymes pikies 'bardzo dobry, doskonały' [PKL, s. 266], jid. Cymes pikies;

3) hoch mit den pjentes 'człowiek zarozumiały, hochsztapler' [BMM, s. 101], jid. Hobn emecn in der linken pjatke;

4) mazyt top! 'na szczęście' [BMM, s. 136], jid. Mazel tov 'życzenie szczęścia' z heb. mazal tov.

Jeden frazem jest cytatem z języka niemieckiego: ajns, cwaj, draj 'szybko, w mgnieniu oka, raz, dwa, trzy' [PLK, s. 270] - niem. Eis, zwei, drei 'jeden, dwa, trzy'.

\subsection{Kalki}

Jedynie BMM dostarcza przykładów kalk frazematycznych z języków rumuńskiego, por.:

1) Bić głowy 'niepokoić, zaprzątać czym niepotrzebnie czas i uwagę innej osoby' [BMM, s. 53], rum. Nu-mi bate capu!, znane też w gwarach ukraińskich z Bukowiny Karpackiej - Не бий собі голову 'ts.';

2) Robić podanie 'pisać podanie' [BMM, s. 192], rum. Face a propunere;

3) Ruska herbata 'czarna herbata, nieziołowa' [BMM, s. 194], rum. Ceai rusesc;

4) Tak nie istnieje 'tak nie jest, tak nie może być, to niemożliwe' [BMM, s. 104], rum. Asta nu există;

i niemieckiego, por.:

1) Kwaśne ciasto 'zaczyn' [BMM, s. 125], niem. Sauerteig;

2) Proszy bliżyj 'proszę wejść, proszę do środka' [BMM, s. 54], niem. Kommen sie näher;

3) Przyjść na kolejke ‘być tym, na kogo przyszła kolej’ [BMM, s. 183], niem. an die Reihe kommen;

4) Szalone dni 'trzy ostatnie dni karnawału przed Środą Popielcową' [BMM, s. 207], niem. Närrische Tage;

5) Święty Wieczór 'wieczór wigilijny, wigilia' [BMM, s. 218], niem. Heiliger Abend, por. też ukr. Святий Вечір.

Kalkami z języka ukraińskiego, a dokładniej z dialektu huculskiego, są: pót bidy licha 'to jeszcze niewielkie nieszczęście' [BMM, s. 176] oraz siła moca 'na siłę; przy użyciu siły; gwałtownie' [BMM, s. 198]. Schemat huculskich „dwójek słownych" wzmacniających ekspresję przez reduplikację elementu za pomocą synonimu [Janów, 1938, s. 11] odnajdujemy też we frazemie psiakrew sobacza 
[BMM, s. 185]. W polskich gwarach taki efekt dają konstrukcje typu piorun piorunujacy [por. Pluta, 1974].

Według Tadeusza Lehra-Spławińskiego [1914, s. 51] kalką frazematyczną z języka ukraińskiego jest ponadto ciepte twoje stowo 'nie wierzę ci' [PLK, s. 388], 'niespełniona obietnica, obiecanki cacanki' [BMM, s. 65]. Tu jednak doszło równocześnie do skrócenia ukraińskiego przysłowia Obiciw pan dast kożucha, stowo joho tepłe. Jako ukraińską tę jednostkę opisał Edward Rulikowski [1879, s. 160], z kolei Aleksander Fredro [1880, s. 59] określił ją jako gminną.

\subsection{Pólkalki}

W PKL i BMM półkalki z języka niemieckiego są reprezentowane przez trzy jednostki:

1) czytać lewita 'czynić komuś wymówki, skłaniając do zmiany postępowania' [BMM, s. 126], niem. Leviten lesen;

2) mieć recht 'mieć rację' [PLK, s. 274; BMM, s. 189-190], niem. Recht haben oraz

3) iść na szpacirgang 'iść na spacer, spacerować' [PLK, s. 273], niem. Spaziergang gehen.

Pierwszy frazem występuje w tych językach, na które silnie oddziaływały język i kultura niemiecka, por. kasz. - wëczëtac kòmù lewitë, czes. - čist někomu levity, głuż. - levity čitat někomu [Treder, 1989, s. 141]. Zwrot ten nawiązuje do życia zakonnego benedyktynów, którzy doskonalili swoje cechy przez czytanie Księgi Kapłańskiej (niem. Levitikus). Znajdujemy tam napomnienia i nakazy poprawy dla duchowieństwa. Podobnie szeroki zasięg geograficzny ma frazem mieć recht. Jak podaje Kartoteka Stownika gwar polskich Polskiej Akademii Nauk [KSGP], występuje on na Kaszubach, w Wielkopolsce, na Śląsku, w tym też na Śląsku Cieszyńskim, a w Małopolsce na Żywiecczyźnie, w okolicach Limanowej i Myślenic, czyli - uogólniając - tam, gdzie silnie oddziaływał język niemiecki.

Półkalkami z języka ukraińskiego i gwar ukraińskich są następujące jednostki:

1) robić kierynié 'robić nieporządek, bałaganić' [BMM, s. 113], ukr. buk. робити кириню;

2) ahi na twoja głowę! 'wyrażenie niezadowolenia' [BMM, s. 46], ukr. buk. агі на твою голову;

3) Czerwona Niedziela 'tydzień przed Wielkanoca, tzw. Wielki Tydzień' [BMM, s. 70], ukr. buk. червона неділя;

4) Czarna Niedziela 'cały tydzień przed Wielkanocą' [BMM, s. 68] ukr. buk. чорна неділя 'ts.', por. też rum. săptămâna neagră 'tydzień po Wielkanocy'; 
5) dać facki 'zbić' [PLK, s. 272; BMM, s. 72], ukr. дати фаику 'ts.';

6) chodzić jak czerepacha 'niezgrabnie, flegmatycznie' [BMM, s. 69], ukr. череnaxa 'żółw'.

Jako półkalkę z rozszerzeniem o człon porównywany można potraktować jednostkę zsunać się z hłuzdów jak pies ze stomy 'zgłupieć' [PLK, s. 171], która nawiązuje do ukraińskiego з глузду зснутися.

Półkalką z języka rumuńskiego jest wychodzić na pensję 'przechodzić na rentę, iść na emeryturę' [BMM, s. 237], rum. a ieşi la pensie.

\subsection{Zapożyczenia wyrazowe we frazeologii}

Na zasób frazemów południowokresowych z obcymi komponentami składają się też jednostki, które powstały na bazie zapożyczeń leksykalnych z języków:

1) niemieckiego, por.:

- Cuzamen do kupy 'razem' [PLK, s. 270], niem. Zusammen 'całkiem' - ten frazem jest znany także w Wielkopolsce i na Śląsku; wiele poświadczeń znajdziemy w internecie na przypadkowych stronach, co pozwala wnioskować, że jednostka ta, dzięki ekspresywności, rozszerza swój zasięg występowania nie w aspekcie geograficznym, lecz stylistycznym;

- Dać po krzyżbantach 'zbić kogoś' [PLK, s. 272], niem. Kreutzband 'wiązadło krzyżowe' - doszło tu do przetłumaczenia na język polski pierwszej części tego wyrazu (Kreutz - krzyż, tu w znaczeniu 'kręgosłup, plecy');

- Dać pucera 'zbesztać kogoś, udzielić reprymendy' [BMM, s. 72], niem. putzen 'czyścić';

- Iść na hinter 'iść na wagary' [PLK, s. 273], niem. hinter 'poza';

- Iść na wander 'iść na dłuższy spacer, na wycieczkę' [PLK, s. 273], niem. wandern 'wędrować';

- Kajne gadanie 'szkoda mówić' [PLK, s. 267], niem. keine 'żaden';

- Mieć szprechsztof 'być bardzo rozmownym; mieć wiele do opowiadania' [BMM, s. 212], niem. Sprechstoff 'dosłownie: materiał języka, mowy';

- Na hal'p cwel'f 'przekrzywione, na bakier (o nakryciu głowy)' [BMM, s. 96], niem. halb zwölf 'pół do dwunastej';

- Na pas blind 'na los szczęścia, na ryzyko' [PLK, s. 270], niem. blind 'ślepy’;

- Obaj cwaj 'obaj' [PLK, s. 270], niem. Zwei 'dwa';

- Radio szanc 'ekspr. plotkowanie' [BMM, s. 188], niem. Schanze 'rów';

- Szac chłopaka 'dobry, równy, morowy chłopak' [PKL, s. 269], niem. Schatz 1. 'skarb', 2. 'ukochany'; samo szac jest używane w dialekcie śląskim na określnie narzeczonego; 
2) ukraińskiego:

- Bić aż drańcie leca 'bić na kwaśne jabłko' [PLK, s. 271], ukr. дрантя 1. 'stare łachy, łachmany', 2. 'niegodna rzecz';

- Dać bałabuchy 'zbić' [PLK, s. 271], ukr. балабух 'słodkie, wyrośnięte ciasto';

- Kicia łabata 'pieszczotliwy zwrot do miłej, bliskiej osoby' [PLK, s. 267], ukr. лабатий 'z długimi łapami';

- Ćwirkać w oczy 'robić wymówki, wypominać coś komuś' [PLK s. 271], ukr. чвиркати 1. 'pluć', 2. 'bryzgać, chlapać';

- Frajerska makitra 'naiwniak, głupiec' [PLK, s. 267], ukr. мaкímpa 1. 'rodzaj głębokiego, glinianego naczynia do ucierania ciasta', 2. 'głowa człowieka';

- Rozwodzić bałak 'rozmawiać, opowiadać' [PLK, s. 275], ukr. балак 'mowa, gwara';

3) hebrajskiego:

- Maszygine Wojtek 'wariat, chory umysłowo' [PLK, s. 268], heb. meszugene (myszygine, myszygin) 'wariat, pomyleniec';

- Robić mechidry 'robić nieuczciwe interesy' [PLK, s. 202], heb. meches 'opłata', w gwarze lwowskiej 'krętacz';

4) rumuńskiego:

- Zbijać hyndry 'próżnować, snuć się bezcelowo lub wynajdować mało pożyteczne zajęcia dla zabicia czasu' [BMM, s. 99], rum. buk. hondrobéle 'nikomu niepotrzebne, zbędne czynności'.

\section{WIELOKULTUROWOŚĆ FRAZEMATYKI LWOWA I CZERNIOWIEC}

Frazematyka południowokresowa, poza tym, że jest świadectwem kontaktów językowych, utrwaliła również wielokulturowość Galicji Wschodniej i Bukowiny Karpackiej, a zwłaszcza wartościujące nastawienie Polaków w stosunku do innych narodowości. Wpisuje się to w przejawiającą się na różnych płaszczyznach języka i zachowań społecznych uniwersalną opozycję swój-obcy.

We frazeologizmach: odprawiać kuczki 'dąsać się' [PLK, s. 274]; odprawiać boruchy 'siedzieć w odosobnieniu' [PLK, s. 424]; odprawiać burychaty 'kiwać się bezwiednie w pozycji siedzącej' [BMM, s. 60] i ótprawjać burychi 'ts.' [BMM, s. 61] znajdujemy odwołania do judaizmu, a dokładniej do sposobu, w jaki modlą się Żydzi, czyli do kiwania się w pozycji siedzącej. W wymienionych przykładach zostały wykorzystane przekształcone formy męskiego imienia pochodzenia hebrajskiego: Boruch/Baruch > boruchy, burychaty, burychi. Jak podpowiada 
znaczenie frazemu di parch 'z pogardą o biednym Żydzie' [BMM, s. 73], Żydów traktowano z niechęcią. Zwrot robić mechidry [PLK, s. 202], a także jidyszyzmy obecne we lwowskim socjolekcie przestępczym [por. Rak, 2016, s. 138-139] wskazują, że w grupach, które posługiwały się tą odmianą języka, byli również wyznawcy religii mojżeszowej.

Obecne w polszczyźnie Czerniowiec cytaty, kalki i półkalki z języka rumuńskiego w zdecydowanej większości dotyczą sfery urzędowej, są więc świadectwem kontaktów oficjalnych. Na kontakty nieoficjalne, a dokładniej na to, jak Polacy z Kresów Południowo-Wschodnich postrzegali Rumunów, pewne światło rzucają jednostki: tumaneszti z Bukareszti 'żartobliwie o człowieku głupim, ciężko myślącym, tępaku' [PLK, s. 251] oraz grać Giorgia 'udawać Greka' [BMM, s. 91], gdzie Giorg, rum. Gheorghe - Grzegorz. Obydwa przykłady przypisują Rumunom negatywnie wartościowane cechy intelektualne, co być może wynikało z problemów w zakresie komunikacji językowej. Wskazuje na to zresztą pierwsza jednostka, stylizowana na rumuńską.

Na podstawie frazematyki południowokresowej można też w pewnym stopniu wnioskować o relacjach polsko-ukraińskich. Frazemy:

1) Nie daj Boże z Iwana pana 'niechętnie o awansach społecznych' [PLK, s. 390];

2) Nie daj Boże z Iwana pana, a z Maryjki dobrodzijki' 'o wywyższających się ludziach z awansu społecznego' [BMM, s. 104];

3) hojda Maryna [PLK, s. 267; BMM, s. 101] podpowiadaja, że Polacy traktowali Ukraińców z wyższością. Nie ma tu, co prawda, bezpośredniego odwołania do etnonimu Ukrainiec i choronimu Ukraina, ale imiona Iwan i Maryna uruchamiają tego typu konotacje. Dodatkowo znaczenie dwóch pierwszych jednostek (mowa o awansie społecznym) precyzuje, że w społeczności wieloetnicznego Lwowa i Czerniowiec Ukraińcy stanowili grupę niżej sytuowaną biedniejszą. Na postawę Polaków wobec Ukraińców mogły więc wpływać, a także utrwalać ją podziały społeczno-ekonomiczne.

Kolejne frazemy dowodzą, że wielokulturowość Kresów dotyczyła również wątków ludowych. Zanotowane w polszczyźnie Czerniowiec przykłady:

1) baba Jadocha hula 'gęsty opad śniegu; gwałtowna zamieć śnieżna, na ogół podczas pierwszych trzynastu dni marca' [BMM, s. 48];

2) ubierać się jak baba Jodocha 'o ubraniu: nieporządnie, niechlujnie, z wieloma warstwami odzieży, spódnic' [BMM, s. 48-49], nawiązują do mitologii wschodniokarpackiej, w dużej mierze wspólnej dla zamieszkującej tę część Karpat ludności ukraińskiej i rumuńskiej. Jak czytamy

\footnotetext{
1 Według NKPP [II, s. 790] jest to przysłowie ukraińskie.
} 
w pracy Ukraińska mifologija Walerija M. Wojtowicza [Vojtovič, 2005], w wierzeniach karpackich ważną postacią była Jodocha (żona Jariły, Rumuni nazywali ją Dochea), która zamieszkiwała najwyższe szczyty gór. Na wiosnę trzepała swoją pierzynę, dlatego w dolinach pojawiały się śnieżyce. Jako odpowiednik pierwszego z frazemów można podać ukraińskie przysłowie Явдоха хвостом крутить - буде пізня вісна [Vojtovič, 2005, s. 612]. Pojawianie się ogona w wizerunku Jodochy (Jawdochy) łączy ją z ogólnosłowiańskim smokiem, bóstwem akwatycznym, które bytuje w chmurach i sprowadza wichury i ulewy. Z kolei informacje o jej odzieży wskazują na pewne związki z czarownicą - zaniedbana, brudna odzież to jej stały atrybut. Jako synonim frazemu ubierać się jak baba Jodocha można potraktować ubierać się jak ciocia l'utrowa 'nieporządnie, niechlujnie, z wieloma warstwami odzieży' [BMM, s. 66]. Tu jednak mamy do czynienia z odniesieniem do luteranizmu jako religii obcej Polakom - niemieckiej.

\section{PODSUMOWANIE}

Poza cytatami, kalkami, półkalkami frazematycznymi i zapożyczeniami wyrazowymi polszczyzna południowokresowa zawierała też frazemy stylizowane na zapożyczenia. Dotyczy to przykładu iść de pache 'iść pod rękę' [PLK, s. 72-273], który ze względu na akcent na ostatnią sylabę miał być galicyzmem, a także już cytowanych wyżej quasi-rumuńskiego tumaneszti z Bukareszti i quasi-włoskiego di parch.

Ogólnie rzecz ujmując, frazemy południowokresowe, w których pojawiają się obce wpływy, można podzielić na dwie grupy. Z jednej strony mamy do czynienia z jednostkami charakterystycznymi dla przedwojennego Lwowa i Czerniowiec, nieznanymi właściwie poza tymi miastami czy szerzej - poza Galicją Wschodnią i Bukowiną Karpacką. Jest to szczególnie widoczne we frazematyce nawiązującej do języka rumuńskiego. Jak wiadomo, wpływy rumuńskie w polszczyźnie ogólnej są - w porównaniu z zapożyczeniami z innych języków - marginalne. W gwarach Podtatrza jest ich nieco więcej na skutek migracji pasterzy wołoskich. Z drugiej strony frazematyka południowokresowa $\mathrm{z}$ wpływami niemieckimi wykazuje pewne podobieństwo do frazematyki dialektalnej tych części Polski, które były wystawione na silne oddziaływanie języka niemieckiego (chodzi tu zwłaszcza o dialekt śląski).

Patrząc na omawiany materiał z innej perspektywy, można stwierdzić, że zapożyczenia ukraińskie, hebrajskie i z jidysz w zdecydowanej większości mają charakter ekspresywny i wartościujący. Na przeciwległym biegunie sytuują się zapożyczenia z języka rumuńskiego, które tworzą zasób frazematyki wpisującej się w sferę leksyki urzędowej. Z kolei pośrodku znajdują się zapożyczenia niemieckie. 


\section{ROZWIĄZANIA SKRÓTÓW}

Skróty konwencjonalne

buk. - bukowiński (gwary ukraińskie lub rumuńskie na Bukowinie Karpackiej)

czes. - czeski

eksp. - ekspresywne

głuż. - górnołużycki

heb. - hebrajski

jid. - jidysz

kasz. - kaszubski

niem. - niemiecki

rum. - rumuński

ts. $\quad-$ to samo znaczenie

ukr. - ukraiński

\section{Źródła}

BMM - Feleszko Kazimierz, 2003, Bukowina moja mitość, t. 2: Stownik, E. Rzetelska-Feleszko, red., Instytut Slawistyki Polskiej Akademii Nauk, Warszawa.

KSGP - Kartoteka Stownika gwar polskich, http://rcin.org.pl/publication/ 37156 (dostęp: 31.03.2019).

NKPP - KRZYŻANOwSKI Julian, red., 1969-1978, Nowa księga przystów i wyrażeń przystowiowych polskich, t. I-IV, Państwowy Instytut Wydawniczy, Warszawa.

PLK - Kurzowa Zofia, 1983, Polszczyzna Lwowa i kresów poludniowo-wschodnich do 1939 roku, Państwowe Wydawnictwo Naukowe, Kraków.

\section{BIBLIOGRAFIA}

Chlebda Wojciech, 2010, Frazematyka, w: J. Bartmiński, red., Wspótczesny język polski, Wydawnictwo Uniwersytetu Marii Curie-Skłodowskiej, Lublin, s. 335-342.

FeleszKo Kazimierz, 2002, Bukowina moja miłość, t. 1: Język polski na Bukownie Karpackiej do 1945 roku, A. Żor, red., Instytut Slawistyki Polskiej Akademii Nauk, Warszawa.

Fredro Aleksander, 1880, Zapiski starucha, w: tegoż, Dzieła, t. X, Gebethner i Wolff, Warszawa. 
Greń Zbigniew, Krasowska Helena, 2008, Stownik górali polskich na Bukowinie, Instytut Slawistyki Polskiej Akademii Nauk, Fundacja Slawistyczna, Warszawa.

JANów Jan, 1938, Wpływ słownictwa rumuńskiego na Podkarpacie, osobliwie na gwarę huculska. II: Pochodzenie Hucułów w świetle zapożyczeń, „Sprawozdania Towarzystwa Naukowego we Lwowie", t. XVII, nr 1, s. 15-27.

KrasowsKa Helena, 2000, Uwagi o sytuacji językowej w Pance, w: K. Feleszko, red., O Bukowinie. Razem czy oddzielnie?, Pilski Dom Kultury, Instytut Filologii Słowiańskiej Uniwersytetu Warszawskiego, Warszawa-Piła, s. 327-332. KrasowsKa Helena, 2004, Sytuacja języka polskiego w kilku miejscowościach na Bukowinie pótnocnej zamieszkatych przez Górali bukowińskich, w: S. Iachimovschi, E. Wieruszewska, red., Relacje polsko-rumuńskie. Materiały z sympozjum / Relaţii polono-române. Materialele simpozionului, Związek Polaków w Rumunii, Suczawa, s. 95-104.

KrasowsKa Helena, 2005, Stan badań językowych grupy górali bukowińskich, w: S. Iachimovschi, E. Wieruszewska, red., Blizej siebie. W kręgu relacji polsko-rumuńskich / Masi aproape unii de alţii. In lumena relatiilor polono-române, Związek Polaków w Rumunii, Suczawa, s. 25-32.

KrasowsKa Helena, 2006, Górale polscy na Bukowinie Karpackiej. Studium socjolingwistyczne i leksykalne, Slawistyczny Ośrodek Wydawniczy, Warszawa.

KrasowsKa Helena, 2010a, Język Polaków na Bukowinie Karpackiej, „Studia z Filologii Polskiej i Słowiańskiej”, t. 45, s. 175-186.

Krasowska Helena, 2010b, Sytuacja socjolingwistyczna Polaków bukowińskich, „Acta Baltico-Slavica”, t. XXXIV, s. 185-195.

LeHr-SpŁawiŃski Tadeusz, 1914, O mowie Polaków w Galicyi Wschodniej, „Język Polski”, R. 2, s. 40-51.

OBARA Jerzy, 1986, Hybrydy i pótkalki na tle innych jednostek językowych obcego i rodzimego pochodzenia, w: S. Warchoł, red., Formacje hybrydalne w językach słowiańskich, Uniwersytet Marii Curie-Skłodowskiej, Wydział Humanistyczny, Lublin, s. 59-73.

OBARA Jerzy, 1989a, Teoretyczne problemy kalkowania, Wydawnictwo Uniwersytetu Wrocławskiego, Wrocław.

OBara Jerzy, 1989b, Kalka jako jeden z przejawów interferencji językowej, „Rozprawy Slawistyczne”, t. 4, s. 185-210.

Pluta Feliks, 1974, Zwroty tautologiczne w języku polskim na tle stowiańskim, „Prace Filologiczne”, t. XXV, s. 437-440.

RaK Maciej, 2009, Frazeologia w Stowniku Kazimierza Feleszki, w: S. Iachimovschi, E. Wieruszewska-Calistru, red., Polska i Rumunia-od historycznego 
sasiedztwa do europejskiego partnerstwa. Materiały z sympozjum / Polonia şi România - de la vecinătatea istorică la parteneriatul european. Materialele simpozionului, Związek Polaków w Rumunii, Suczawa, s. 297-306.

RAK Maciej, 2010, Zapożyczenia we frazeologii polszczyzny Lwowa na materiale „Stownika” Z. Kurzowej, w: P. Gricenko, N. Hobzej, red., Diałektołogiczni studiji 9: Zapozyczennia ta interferencija, Instytut Ukrajinoznawstwa im. I. Kripiakewycza NANU, Lwiw, s. 105-112.

RAK Maciej, 2016, Kilka uwag o socjolekcie przestępczym polszczyzny przedwojennego Lwowa, „Socjolingwistyka”, t. 30, s. 133-145.

RULIKowski Edward, 1879, Zapiski etnograficzne z Ukrainy, „Zbiór Wiadomości do Antropologii Krajowej", t. III, cz. 3, s. 62-166.

SeIfFerT-Nauka Irena, 1992, Dawny dialekt miejski Lwowa, cz. 1: Gramatyka, Wydawnictwo Uniwersytetu Wrocławskiego, Wrocław.

Staszewski Stanisław, 1985, Pótkalki, kalki, zapożyczenia i hybrydy we frazeologii, w: M. Basaj, D. Rytel, red., Z problemów frazeologii polskiej i stowiańskiej II, Zakład Narodowy im. Ossolińskich, Wydawnictwo Polskiej Akademii Nauk, Wrocław-Warszawa-Kraków-Gdańsk-Lódź, s. 215-218. Szturm de Sztrem Edward, red., 1932, Wiadomości statystyczne Głównego Urzędu Statystycznego 1932, Nakładem Głównego Urzędu Statystycznego, Warszawa.

TREDER Jerzy, 1989, Frazeologia kaszubska a wierzenia i zwyczaje (na tle porównawczym), Muzeum Piśmiennictwa i Muzyki Kaszubsko-Pomorskiej w Wejherowie, Towarzystwo Przyjaciół Ziemi Wejherowskiej, Wejherowo. VoJtowycz Walerij, 2005, Ukrajins'ka mifołogija, Lybid', Kyjiw, https://uk.wikipedia.org/wiki/Населення_Чернівців (dostęp: 25.03.2019).

\section{Maciej Rak}

\section{WIELOJĘZYCZNOŚĆ I WIELOKULTUROWOŚĆ PRZEDWOJENNEGO LWOWA I CZERNIOWIEC W ŚWIETLE FRAZEMATYKI}

\section{Streszczenie}

Artykuł dotyczy frazematyki polszczyzny przedwojennego Lwowa i Czerniowiec. Miasta te były wielojęzyczne i wielokulturowe, a język polski był tam reprezentowany przez dialekt południowokresowy. Obce wpływy we frazematyce Lwowa i Czerniowiec dają się ująć jako cytaty, kalki, półkalki, a także zapożyczenia leksykalne, na podstawie których powstały frazemy. Ogólnie rzecz ujmując, omówione w artykule jednostki można podzielić na dwie grupy. Z jednej strony mamy do czynienia $\mathrm{z}$ frazemami charakterystycznymi dla przedwojennego Lwowa i Czerniowiec, nieznanymi 
właściwie poza tymi miastami czy szerzej - poza Galicją Wschodnią i Bukowiną Karpacką. Jest to szczególnie widoczne we frazematyce nawiązującej do języka rumuńskiego. Z drugiej strony frazematyka południowokresowa $\mathrm{z}$ wpływami niemieckimi wykazuje pewne podobieństwo do frazematyki dialektalnej tych części Polski, które były wystawione na silne oddziaływanie języka niemieckiego.

\title{
MULTILINGUALISM AND MULTICULTURALISM IN PRE-WAR LVIV AND CHERNIVTSI IN THE CONTEXT OF PHRASEMATICS
}

\begin{abstract}
Summary
This article concerns the phrasematics of the Polish language of pre-war Lviv and Chernivtsi. These cities were multilingual and multicultural, and Polish language was represented there by the SouthEastern dialect. Foreign influences in Lviv and Chernivtsi phrasematics can be summarized as: citation, calque, half-calqua, as well as lexical borrowings, on the basis of which phrasemes were created. In general, the phrasemes discussed in the article can be divided into two groups. On the one hand, we deal with phrasemes characteristic of pre-war Lviv and Chernivtsi, unknown beyond these cities or, more broadly, outside of Eastern Galicia and Bukovina. This is particularly evident in the phrasematics referring to the Romanian language. On the other hand, the phrasematics of the South-Eastern dialect with German influences shows some similarity to the dialectal phrasematics of those parts of Poland which were exposed to the strong influence of the German language.
\end{abstract}

